\title{
SAITAMA E O ENIGMA DO MESTRE
}

Danilo Bantim Frambach*

RESUMO: O presente trabalho busca analisar, a partir de uma perspectiva filosófica, o herói Saitama, personagem principal da série de anime e mangá One-Punch Man, sua busca por ser um herói e o seu papel como mestre do ciborgue Genos. À primeira vista, dizer que a relação entre eles constitui de fato a de um mestre e um discípulo, parece um tanto exagerada: apesar de ser visto assim por Genos, Saitama não acredita que tenha qualquer conhecimento a ensinar para o seu autointitulado discípulo. Além disso, apesar de toda sua força, Saitama é atormentado constantemente por um tédio profundo, resultado da incapacidade de encontrar novos desafios como herói. No entanto, acreditamos haver mais em Saitama do que apenas "o herói mais forte". Ao nos voltarmos para nossa história, vemos que um dos maiores mestres da humanidade também acreditava nada saber: o Sócrates apresentado por Platão afirmava, constantemente, sua própria ignorância. Resta a pergunta: como pode a figura do mestre, representação própria do saber humano, ser ligada a homens que só reconhecem nada saber, e no caso específico de Saitama, nada ter a ensinar?

Palavras-chave: Mestre; Enigma; Filosofia da Educação; Sócrates; One-Punch Man.

\section{SAITAMA AND THE MASTER'S ENIGMA}

\begin{abstract}
The present work seeks to analyze, from a philosophical perspective, the hero Saitama, the main character of the anime and manga series One-Punch Man, his quest to become a hero and his role as master of the cyborg Genos. At first glance, to say that the relationship between the two does in fact constitute that of a master and a disciple seems somewhat exaggerated: despite being seen like a master by Genos, Saitama does not believe that he has any knowledge to teach to his self-titled disciple. Moreover, despite all his strength, Saitama is constantly tormented by a deep boredom, result of his inability to find new challenges as a hero. However, we believe there is more to Saitama than just "the strongest hero". As we turn to our history, we see that one of humanity's greatest teachers also believed he knew nothing; Plato's Socrates constantly asserted his own ignorance. We are thus left with a question: How can the master's image, which represents human knowledge, be linked to men who do only recognize their own ignorance, and in Saitama's specific case, nothing to teach?
\end{abstract}

Key-words: Master; Enigma; Philosophy of Education; Socrates; One-Punch Man.

* Possui doutorado em Filosofia pela Universidade do Estado do Rio de Janeiro (UERJ). Professor Adjunto de Filosofia da Educação da Universidade do Estado do Rio de Janeiro (UERJ).dan.bantim@gmail.com

ORCID: https://orcid.org/0000-0002-4410-9599 
O que é um bom professor? No que constitui sua prática? Quais os limites de tal tarefa? O que é, afinal, ser mestre de alguém? Tais questões, acreditamos, já foram ou ainda são objeto de preocupação de todo aquele que decidiu seguir carreira no magistério, e não raro é buscar exemplos, seja em nossa experiência pessoal, seja em fontes externas, para obter possíveis respostas para essas interrogações. Assim, como uma dessas fontes externas, e extremamente presente em nosso cotidiano, a cultura nerd nos apresenta inúmeras figuras que assumem o papel de mestre: desde aqueles que usam o título propriamente dito, como Mestre Kame e Professor Xavier, até aqueles que não o fazem, como é o caso Sr. Miyagi. Do mais sério e rígido ao mais enigmático e excêntrico, todos esses mestres encarnam a principal característica que se espera de um professor: eles possuem um conhecimento a ser ensinado, comunicado, transmitido aos seus discípulos. Em outras palavras, o mestre é, como está historicamente instituído em nosso senso comum, aquele que traz o conhecimento a ser apresentado ao outro.

Nesse sentido, o protagonista da série de anime e mangá One-Punch Man se destaca de uma maneira um tanto curiosa. Diferentemente dos heróis aos quais estamos acostumados, Saitama se tornou forte forte demais, como a série não cessa de destacar - mas não sabe exatamente como ${ }^{1}$. Além disso, não assume para si o posto de mestre, mas sim é alçado a tal posição por Genos, um ciborgue que busca vingança e que, impressionado com a força de Saitama, decide unilateralmente que ele será agora seu mestre. Parte dos momentos cômicos da série vêm justamente dessa improvável relação entre aquele que busca aprender o caminho para se tornar mais forte e aquele que tem plena consciência de que não possui o que ensinar (afinal, o treinamento físico de Saitama de nada adiantaria para fortalecer alguém cujo corpo é mais máquina do que humano). Ao reconhecer que não possui o que ensinar ao seu discípulo, Saitama parece remontar um momento muito próprio de nossa história, ecoando, em certa medida a famosa resposta de Sócrates ao Oráculo: "só sei que nada sei”.

\section{O Engima Socrático: paixão e interrogação}

Em Os Enigmas da Educaşão, Lílian do Valle dedica sua análise para a interrogação do papel e do lugar da filosofia no meio educacional. Para isso, Valle apresenta uma releitura de três diálogos platônicos (Mênon, Górgias e Protágoras), destacando em cada um deles os enigmas que dão título à obra. Voltando sua atenção para o Górgias, a autora destaca o enigma do mestre e a árdua tarefa de conceber-se como tal. No diálogo, vemos o debate entre o sofista e Sócrates, que é guiado pela questão lançada pelo filósofo: "[...]Desejo perguntar-lhe em que consiste a força de sua arte e o que é que ele professa e ensina" (PLATÃO, 1980, 447b-c).

\footnotetext{
${ }^{1}$ Saitama acredita que a força dele - capaz de aniquilar sem qualquer esforço qualquer adversário com um simples soco, como já adianta o título - venha do árduo treinamento físico que ele realizou ininterruptamente por três anos. No entanto, todos os que ouvem seu relato destacam a mundanidade de seu treinamento, e ressaltam que seria impossível para alguém atingir tamanho poder apenas com aquilo.
} 
O filósofo se volta, assim, para Górgias: ‘...de que nome é preciso te chamar e qual é a arte cujo conhecimento te vale tal denominação’? Não há, da parte de Górgias, qualquer hesitação: 'Minha arte, Sócrates, é a arte oratória!', responde-lhe prontamente. 'É portanto de rhétor (orador) que te devemos apelidar?'. E Górgias, desafiante: 'E, mesmo, de bom orador!'. É que, tal como Protágoras, Górgias proclama abertamente sua profissão e o orgulho com o qual a pratica na pólis democrática, onde tanto a retórica quanto a sofística ganham projeção cada vez maior. (VALLE, 2002, pp.117,118).

Conhecida como a arte da persuasão no discurso, a retórica é um dos principais recursos dos sofistas. Contudo, "Sócrates está empenhado em fazer com que Górgias admita que a exigência máxima, e única, do discurso lhe é dada [...] pelo objeto que a funda: cada arte (como a medicina e a ginástica, por exemplo) é definida, propõe-lhe Sócrates, por um discurso 'relativo à coisa de que cada uma delas é a arte" (VALLE, 2002 p.123). Ao longo do diálogo, Platão nos apresenta a conclusão de que a retórica peca por não se fazer um saber seguro, não constituindo, assim, uma arte. Consequentemente, o mestre que dela se dispõe de fato não educa, mas realiza uma antieducação. Em suma, o mestre da retórica não apenas não ensina, mas também deforma os alunos, fazendo com que eles não aprendam.

É a partir da crítica platônica aos sofistas que a construção sistemática da imagem do mestre idealizado se revela. Como destaca Jaeger:

Sócrates é ao mesmo tempo justo e moderado, valente e piedoso. A sua vida é combate e serviço de deus a um tempo. Não descuida dos deveres do culto aos deuses, o que the permite dizer a quem só é piedoso neste sentido externo que há um temor de Deus mais alto do que este. Lutou e distinguiu-se em todas as campanhas de sua pátria; isto o autoriza a fazer compreender aos mais altos chefes do exército ateniense que não são as vitórias obtidas pela espada na mão as únicas que o Homem pode alcançar. É por isso que Platão distingue as virtudes comuns do cidadão e a elevada perfeição filosófica. Sócrates é para ele a personificação deste super-homem moral; o que Platão diria, no entanto, era que só ele possuía a "verdadeira" areté humana. (JAEGER, 1995, p.566).

E como complementa Valle:

Se a figura do mestre é admirável, se ele é o verdadeiro político e o verdadeiro legislador, é porque não há forma mais nobre de servir à pólis do que educar seus cidadãos, de forma que suas almas sejam «as mais belas possíveis». O ideal filosófico se faz prática educativa e, desta forma, realiza plenamente o mais alto ideal de cidadania. (VALLE, 2002, p.187).

A figura de Sócrates, por si mesma, já é cercada de mistérios e enigmas; por exemplo, não fica claro onde, nos diálogos de Platão, termina a figura do Sócrates real e onde começa a imagem dele que o seu mais famoso discípulo construiu². Aqui, nos interessa, no entanto, um dos paradoxos mais importantes que cercam o famoso filósofo, estabelecido por meio dos textos de Platão: como poderia ser mestre aquele que só reconhece sua própria ignorância? Como identificar tal indivíduo com a imagem que representa a própria identidade do saber humano?

\footnotetext{
${ }^{2}$ Como destaca Valle (2002, p.189) e reconhece Jaeger (1995, p.541), perto do desfecho do Górgias, a personagem de Sócrates começa um autoelogio que acaba por contradizer as afirmações que o filósofo constantemente faz sobre si mesmo, lançando, sobre a figura idealizada do mestre, a suspeita de sua falsidade.
} 
Sócrates afirma, constantemente, não possuir nada além de sua interrogação sobre a verdade; Além disso, só pôde aceitar a afirmação do oráculo, quando compreendeu que a verdadeira sabedoria residia no reconhecimento de sua própria ignorância ${ }^{3}$. Essa figura representa "todo ideal filosófico que não se contaminou inteiramente com os apelos da facilidade. E também, todo professor que encarna, a seu modo, o eros do conhecimento, no combate e na reconciliação diária entre Póros e Penía, entre o recurso e a indigência, entre o abismo da criação e os limites da existência humana" (VALLE, 2002, p.190).

Assim, destaca-se a primeira grande característica do mestre idealizado: a valorização da interrogação. Ela não é pura técnica, como Platão determina que é a prática dos sofistas, mas razão que interroga, e interroga constantemente. No entanto, não buscamos apenas a interrogação. Todo aquele que se interroga busca, também, as respostas, e de tal forma que, ao alcançá-las, descobrimos a gigantesca dificuldade de não encerrarmos nelas o nosso pensamento. Assim, Castoriadis provoca:

O que, então, é investido pela paixão de conhecer? A primeira resposta que se apresenta é, evidentemente: a verdade. E não é necessário entrar na discussão filosófica da questão: o que é a verdade? para afirmar, em primeira aproximação, que a verdade tem a ver com os resultados de conhecer. Mas é aqui que os paradoxos reaparecem. A paixão da verdade... pode conduzir, e mais freqüentemente o conduz, a uma fixação nesses... resultados, com os quais o sujeito acaba por se identificar, ao ponto que qualquer questionamento pode ser ressentido como um questionamento de sua própria identidade, de seu próprio ser. O narcisismo do sujeito se estende necessariamente até englobar - e não somente no domínio do conhecimento - os produtos do sujeito, que passam a ser a partir de então objetos de um investimento categórico e incondicional. (CASTORIADIS, 1999, p.75).

$\mathrm{Na}$ Apologia, Sócrates deixa claro que é preferível ser ignorante a pretender tudo saber:

Enfim, fui procurar os profissionais. Se, em meu interior, estava efetivamente consciente de nada saber, sabia bem, por outro lado, dever encontrar entre eles alguns que conheciam uma quantidade de belas coisas. E, nisso, não me enganei: eles conheciam, ao contrário, coisas que eu desconhecia inteiramente e, deste ponto de vista, eles eram mais sábios do que eu! Foi, no entanto, minha opinião, atenienses, que o erro dos poetas era exatamente aquele desses excelentes profissionais: cada um deles, porque exercia com perfeição sua arte, julgava também possuir, para todo o resto, uma sabedoria acabada, e isto em relação às coisas que têm muito maior importância! Esta pretensão impertinente manchava sua outra sabedoria, de tal forma que eu me dizia, lembrando do oráculo, que preferia ser como sou, nem sábio da sabedoria das pessoas de que falo, nem ignorante de sua ignorância, do que ser os dois a uma só vez: o que é seu caso! A mim mesmo, como ao oráculo, respondia, portanto, que minha vantagem era ser como sou. (PLATÃO, Apologia, 22c-e, apud. VALLE, 2002, pp.191,192, grifo da autora).

Apesar de suas mais enfáticas afirmações, Sócrates não foi reconhecido por seus discípulos e contemporâneos apenas como aquele que "só sabe que nada sabe", mas principalmente, como aquele capaz de levá-los à sabedoria. E só pôde ser assim porque a interrogação socrática - tarefa da figura idealizada do filósofo e do mestre - implicava também, além do rigor e da indagação constante, uma modificação profunda. Modificação essa capaz de converter a interrogação em objeto do próprio desejo

${ }^{3}$ PLATÃO, Apologia, 22e. 
e transformar radicalmente os indivíduos que ela constitui. Em outras palavras, Sócrates assumiu para a posteridade o lugar de mestre, porque fez da interrogação não só a sua razão de ser, mas também o objeto próprio de sua paixão:

'Se vós me dissésseis, Sócrates, nós te deixamos livre, à condição de que abandones esta pesquisa e que não filosofes mais... eu vos diria... que não deixarei de filosofar... a vida sem exame não é vivível (o de anexetastos bios ou biôtos)'4. Sócrates morre sem dúvida em função de muitos fatores e motivos, mas sobretudo porque o exame, a interrogação, se transformaram em objetos de sua paixão, aquilo sem o quê a vida não vale a pena ser vivida. Insistamos: Sócrates não fala de verdade, ele sempre proclamou, ainda que ironicamente, que a única coisa que sabia com certeza era que não sabia nada. Ele fala de exetasis, exame, pesquisa... a paixão, fazendo que seu objeto valha a vida; e a natureza deste objeto, não como posse, mas como busca e pesquisa, atividade examinante. (CASTORIADIS, 1999, pp.136,137).

\section{A vida de Saitama: o vazio do herói mais forte}

Se Sócrates é um grande mestre e filósofo por saber claramente o objeto de sua paixão e por não abandoná-lo mesmo quando sua vida é ameaçada, o mesmo não podemos dizer sobre o herói Saitama. Ao longo de duas temporadas de anime e de mais de vinte volumes de mangá 5 , One-punch Man narra o coditiano de Saitama, um jovem que vive em um mundo assolado por criaturas - monstros, catalogados pelo nível de ameaça que representam e que atacam constantemente as cidades e as pessoas - que desde pequeno sonhava em ser um herói capaz de derrotar o mal com apenas um golpe. Como é narrado logo no segundo capítulo da obra, Saitama era um jovem desempregado que já não se importava com mais nada. Após uma entrevista de emprego fracassada ele se depara com uma criatura que procura matar uma criança, e é nesse momento que, ao lembrar de seu sonho de infância, o protagonista decide salvá-la. Após esse evento, ele decide dedicar-se ao sonho de se tornar um herói. O capítulo conclui com Saitama relembrando o evento, e apesar de ter alcançado seu sonho, há algo de errado: - Acho que isso foi há uns três anos... Treinei duro, como se não houvesse amanhã, até ficar careca, e consegui me tornar invencível. Hoje, sou o herói que sempre sonhei ser. Mas, então, por que não me sinto realizado...? (ONE, MURATA, One-Punch Man, 2016, Vol.1, cap.2).

Dentre suas características, duas chamam mais atenção em Saitama, tornando-o uma figura singular entre os super-heróis: a primeira é o seu poder. Saitama é a personificação do poder absoluto ${ }^{6}$. Diferente de outros heróis, ele não possui qualquer dificuldade para vencer seus adversários, encerrando a maioria de suas lutas com um simples soco sem esforço ${ }^{7}$. Isso faz com que Saitama funcione como um

\footnotetext{
${ }_{4}^{4} \mathrm{Na}$ primeira frase, Castoriadis cita um trecho da Apologia, 29c-d.

${ }^{5}$ Até o momento, apenas vinte e um volumes foram oficialmente traduzidos e publicados no Brasil pela Panini Comics. Quanto ao anime, a primeira temporada está disponível dublada no serviço de streaming Netflix, e ambas se encontram legendadas em outro serviço de streaming, o Crunchyroll. Utilizaremos o mangá como principal fonte de referência para este trabalho. Para facilitar as referências, seguiremos a numeração sequencial dos capítulos, como presente em cada volume. Tanto o anime quanto o mangá ainda estão em produção, isto é, a história ainda não foi concluída.

${ }^{6}$ Em determinado momento da história, quando o protagonista faz o teste para entrar na Associação de Heróis, um dos avaliadores comenta que "é como se um Deus habitasse o corpo dele" (Vol.3, cap.16).

${ }^{7}$ O fato de Saitama não se esforçar nas lutas fica claro pelo próprio traço utilizado por Yusuke Murata para retratá-lo:
} 
"anticlímax" da série, resolvendo facilmente os árduos embates e dificuldades com os quais os outros heróis se deparam.

A segunda característica mais marcante do herói é consequência da primeira. Ao tornar-se tão forte quanto sempre sonhou, Saitama para de encontrar desafios, lançando sua existência num vazio e tédio absolutos:

\begin{abstract}
- O mal que infesta este mundo não dá sinais de que desaparecerá. Nada mudou desde que me tornei herói por hobby ${ }^{8}$. Em outras palavras, não teve impacto algum na sociedade. Não que eu fique triste, afinal, sou um herói por hobby. Faço o que faço apenas pra satisfazer meu ego. Sob o pretexto de defender a justiça, minha luta contra o mal proporcionou euforia e prazer quando eu havia perdido a vontade de viver. Mas agora... Sinto uma enorme angústia... minhas emoções estão entorpecidas. Não sinto medo nem alegria. Nem nervosismo... nem raiva. [...] Quando enfrento criaturas e monstros, não existe um embate de verdade. Parece até... quando matamos um mosquito. Não sentimos nada. (ONE, MURATA, Vol.1, cap.5).
\end{abstract}

Com efeito, à primeira vista, One-Punch Man nos apresenta um protagonista deprimido, refém da ausência de desafios gerada por se conquistar um sonho. No entanto, tal figura começa a mudar com o aparecimento de Genos, um jovem de dezenove anos que decidiu se tornar um ciborgue após ter seu vilarejo e sua família destruídos por um outro ciborgue. Movido por um desejo de vingança, Genos viaja pelo mundo à procura de pistas daquele que acabou com o seu lar e a sua família. Autointitulado como "ciborgue da justiça", o jovem luta contra qualquer criatura que aparece no caminho dele e atrapalha a sua busca por vingança. É justamente em um embate com uma criatura que ele, por coincidência, conhece Saitama. Prestes a se autodestruir, como medida desesperada de derrotar um adversário que não era capaz de vencer, Genos é salvo pelo protagonista que, com um só golpe, obviamente, derrota a criatura. Abismado com a força descomunal de Saitama, Genos pede para ser seu discípulo e passa a segui-lo, na esperança de se tornar mais forte. É a partir desse encontro que passamos a ver outras camadas do "Careca de capa".

Com a presença constante de Genos, Saitama abandona o comodismo e passa a participar passa a participar de torneios de artes marciais, transformando seu hobby em profissão, ao entrar para a associação de heróis, onde ele acredita conseguir um pouco mais de estímulo para sua vida. É nesse ponto que se revela algo muito curioso sobre o protagonista: sendo um herói por hobby, Saitama nunca procurou reconhecimento pelos seus feitos, e desconhece por completo a existência de uma associação que não só reúne os heróis do mundo, mas lhes paga um salário pelos seus serviços - o que só reforça quão desprendido do mundo é Saitama.

simples e sem detalhes, contrapondo-se à riqueza do traço das demais personagens.

${ }^{8}$ Esse é outro aspecto curioso da personagem. Enquanto a maioria dos super-heróis são convocados por algum tipo de chamado maior (responsabilidade, justiça, vingança, etc.), Saitama decide ser herói como um passatempo.

${ }^{9}$ Nome de herói de Saitama, dado a ele pela Associação de Heróis. 


\section{O Mestre que não tem o que ensinar ou aprender}

Diante da insistência do novo "discípulo”, Saitama resolve ensinar o segredo de sua força, o árduo treinamento físico que ele realizou por três anos: “- Cem flexões de braço! Cem abdominais! Cem agachamentos! Além disso, mais dez quilômetros de corrida. Tem que fazer isso todo santo dia! (ONE, MURATA, Vol.2, cap.11)".

O grande problema, e a indignação que tal revelação causa em Genos é facilmente explicada. Por um lado, o poder avassalador de Saitama vem - ou ao menos é o que ele acredita - de um treinamento físico comum; por outro lado, Genos é um ciborgue, cujo corpo foi totalmente substituído por partes mecânicas. Isso, no mundo de One-Punch-Man, significa que ele não se fortalece ao fazer exercícios, mas ao atualizar seus componentes.

Apesar desta revelação, Genos não têm dúvidas de que há alguma outra coisa que justifique o poder de seu mestre, mesmo que Saitama não se dê conta. Assim, o ciborgue não somente passa a acompanhar o mestre, mas também a dividir o mesmo apartamento, mantendo um diário de anotações, no qual registra os "ensinamentos e o conteúdo" de seu treinamento ${ }^{10}$. A partir daí, começamos a ver um conflito nascer no interior do protagonista que se vê obrigado a ensinar alguma coisa... qualquer coisa:

- Não tenho nadinha pra ensinar ao Genos. Sinto que estou enganando ele. Tenho até vergonha de continuar me portanto como um mestre. Pense! Deve haver algum método de treinamento ou espiritualidade convincente. Nem que seja uma porcariazinha qualquer! Ah, não dá! Não consigo pensar em nada além de treinamento físico! Afinal, foi só o que eu fiz. Mas o Genos não vai se conformar com uma coisa dessas. (ONE, MURATA,Vol. 3, cap.18).

Diante da farsa na qual julga se encontrar, Saitama se vê obrigado a "inventar" alguma coisa que distraia seu discípulo, e assim dá a ele a missão de ascender no mundo dos heróis profissionais. Neste, a força e poder de combate valem mais que qualquer coisa. Dessa forma, aquilo que inicialmente, para Saitama, era uma nova forma de conseguir algum estímulo para sua vida, se torna mais uma fonte de tédio. Se para crescer no mundo dos heróis é preciso de força, isso que ele já possui até demais, Saitama se vê na posição de quem não tem mais como crescer.

Dessa forma, na qualidade de mestre, Saitama percebe uma dura realidade para si: a estagnação. Não tendo como evoluir, ele não tem mais nada a ensinar além do que já fez, mas isso implica, também, a inutilidade de tentar aprender algo novo. Assim, Saitama se mostra, inicialmente, como uma espécie de “anti-Sócrates": aparentemente, não possui qualquer paixão, tornando-se apático; não precisa aprender, posto que já possui todo o poder. Por fim, reconhece ser incapaz de ensinar. No entanto, Saitama não está acomodado com sua situação. Pelo contrário, busca sempre uma saída para o tédio, questionando constantemente o que pode estar faltando para si, como humano e como herói. Como conclui Valle:

\footnotetext{
${ }^{10} \mathrm{O}$ que se resume a anotações sobre as ações mais corriqueiras e cotidianas realizadas por Saitama, como a posição em que ele deita, a forma como segura um mangá, etc.
} 
O conhecimento nasce da interrogação: quem desconhece esta simples evidência dificilmente estará em condições de prestar contas daquilo que aprendeu. O conhecimento nasce da interrogação: quem se recusar a reconhecê-lo dificilmente estará em condições de aprender - e, menos ainda, de ensinar. (VALLE, 2002, p.190).

E é aí que Saitama, um mestre que não tem o que ensinar, se revela interessante para pensarmos a tarefa do professor. Afinal, mesmo diante de todas essas limitações autoimpostas, muitas das quais relacionadas à própria condição de herói, Genos aprende com Saitama. Por exemplo, o Vol. 5 do mangá retrata a dura luta da Associação de Heróis contra o Rei do Mar Profundo. O monstro ataca a cidade e derrota inúmeros heróis de todas as classes, incluindo Genos que sacrifica o próprio corpo e a sua capacidade de lutar para salvar uma criança. Quando tudo parece perdido, chega Saitama, e como de costume, resolve tudo com um simples golpe. Contudo, a alegria inicial da população logo se transforma em desdém contra os heróis derrotados diante da força absurda do herói:

- Ele acabou com a criatura com um soco só!

- Como!? Os outros heróis mal conseguiram relar no monstro!

- Vai ver a criatura nem era tão forte assim. [...] Olha para ele, foi derrubado com apenas um golpe por um herói de classe "C". [...] E os heróis que foram vencidos... Apenas ostentam o título de classe "A" ou "S". Não eram fortes de verdade. [...] qualquer um pode arriscar a vida. Mas, se não derrotar os monstros, não pode ser chamado de herói, certo? [...] Na prática, aquele careca resolveu tudo sozinho. Os outros se machucaram à toa. (ONE, MURATA, Vol.5, cap. 28).

Com a população a ponto de ficar contra os outros heróis, Saitama toma uma medida drástica. Em uma profissão em que a imagem e o reconhecimento valem mais que qualquer coisa, o protagonista comete "suicídio"; assume para si o lugar de farsante, afirmando que, só venceu o monstro com um soco, por conta do esforço e sacrifício dos demais heróis.

Graças ao convívio com Saitama, Genos demonstra um claro crescimento pessoal, tornando-se mais empático e paciente. Por mais que não se torne fisicamente mais forte, em decorrência desse convívio, o ciborgue cresce como humano. Ele reconhece que evoluiu, ao presenciar a execução de prisioneiros por parte de outro herói: "Primeiro lugar da classe 'A', o garanhão mascarado Amai-Mask. Ele se parece comigo, antes de conhecer o sensei. Não tem um pingo de piedade. Deve odiar profundamente a existência do mal e sente urgência em exterminá-lo" (ONE, MURATA, Vol.7, cap.37).

Ainda que Saitama não reconheça, há algo que é o objeto de paixão para ele: tornar-se o melhor herói. A estagnação pela qual o protagonista passa só lhe causa incômodo por ele desejar ser herói e por ser apaixonado por seu hobby/profissão. É por isso, que ele sacrifica sua reputação no conflito com o Rei do Mar Profundo; é por isso que ele perde a paciência com Suiryu, no capítulo 70 (vol.13), quando o lutador passa a desdenhar daqueles que escolhem ser heróis profissionais. E é por isso que, após outra 
luta sem emoção e diante da constatação de que não pode mais evoluir ${ }^{11}$, ele recebe conselhos do herói mais improvável de todos, King $^{12}$ :

-[...] Obter satisfação durante a luta não é a essência de um herói. A razão de ser de um herói não é ajudar as pessoas e ser útil ao mundo? E nesse aspecto, mesmo sendo o herói mais forte, você ainda não é o melhor. Você ainda deve evoluir muito até alcançar seu ideal como herói. Que tal? Viu como é superficial e arrogante sua ideia de que evoluiu ao máximo? [...] "O que é ser o melhor herói?". Enquanto não encontrar a resposta para isso, não tem tempo para se entediar. Isso se você tiver a intenção de viver como um herói... Saitama-shi. (ONE, MURATA, Vol.15, cap.77).

\section{Considerações finais}

A dura realidade aprendida por Saitama é a mesma que deve ser aprendida por todo mestre (e já ensinada por Sócrates): da mesma forma que ser um herói não significa apenas possuir poder para derrotar seus adversários, ser professor não significa possuir todo o conhecimento possível. A busca apaixonada de Sócrates pela verdade é espelhada na busca apaixonada de Saitama para se tornar o melhor herói, apesar dessa paixão não ser reconhecida por ele. É exatamente por isso, que Saitama pode ser visto como um mestre por Genos e por nós. Não por se colocar como alguém que nada sabe, como Sócrates, ou por possuir um saber claro e preciso a ser comunicado, como normalmente acreditamos que deva ser o mestre. Mas porque, em sua ignorância sobre si mesmo, e diante do incômodo que a possibilidade de estagnação lhe causa, ele se questiona sobre o objeto de sua paixão:

O Eu não é mais investido como possuidor da verdade, mas como fonte, e capacidade incessantemente renovada, de criação. Ou, o que quer dizer a mesma coisa: o investimento tem por objeto a própria atividade do pensamento, como apta a produzir resultados verdadeiros, mas para além de qualquer resultado parcial. E isso se faz acompanhar por uma outra ideia de verdade, tanto como ideia filosófica, quanto como objeto de paixão. [...] O apego ao verdadeiro é a paixão do conhecimento, ou o pensamento como Eros. (CASTORIADIS, 1999, pp.150,151).

Paixão esta que é a mais autêntica experiência que um professor pode e deve comunicar aos seus alunos.

\footnotetext{
11 O que parece irônico, pois a conclusão de Saitama ao explicitar seu regime de treinamento ainda no Vol.2 do mangá é “Os humanos são fortes porque podem mudar a si mesmos” (cap.11).

${ }^{12} \mathrm{King}$, na verdade, não possui força alguma. Ele ganha o título de "homem mais forte do mundo" e o posto na classe "S" da Associação de Heróis por um mero acaso: era o único presente após Saitama aniquilar um adversário. Portanto, acabou recebendo os créditos pelas vitórias.
} 


\section{REFERÊNCIAS}

CASTORIADIS, Cornelius. «Paixão e Conhecimento», In :Encruzilhadas do labirinto / 5: feito e a ser feito. Rio de Janeiro: DP\&A, 1999.

JAEGER, Werner. Paideía. A Formação do Homem Grego. São Paulo: Martins Fontes, 1995.

PLATÃO. Protágoras - Górgias - O Banquete - Fedão, Tradução de Carlos Alberto Nunes, Universidade do Pará, 1980.

ONE \& YUSUKE M. One-Punch Man, Editora Panini Brasil Ltda. Brasil, Vol. 1-21, 2016-2020.

RANCIÈRE, Jacques. O Mestre Ignorante - cinco lições sobre a emancipação intelectual, Tradução de Lílian do Valle. Belo Horizonte: Autêntica, 2002.

VALLE, Lílian do. Os enigmas da educação: a Paidéia democrática entre Platão e Castoriadis. Belo Horizonte: Autêntica, 2002.

Recebido em: 30 de agosto de 2020. Aprovado em: 20 de outubro de 2020. 